\title{
EDITORIAL DOSSIÊ CONSUMO E SOCIABILIDADES 2
}

$\mathbf{N}$

os dias 25 e 26 de abril de 2019, o Grupo de Pesquisa Consumo e Sociabilidades (ESPM Rio/CNPq) promoveu a II Jornada de Pesquisa sobre Consumo e Sociabilidades. O evento aconteceu no auditório da ESPM/Rio e contou com a participação de pesquisadores de diferentes áreas e instituições que estudam a temática. Em sua segunda edição, a Jornada recebeu propostas de trabalhos de pesquisadores de oito instituições de ensino do Rio de Janeiro, fato que sinaliza para a pertinência do estabelecimento de novos espaços para a discussão de temas ligados ao consumo. O aumento no número de submissões exigiu esforço da comissão organizadora no sentido de ampliar a quantidade de sessões, mas mantendo o espaço qualificado para o debate e a troca de ideias e experiências entre professores, pesquisadores e estudantes, que é o objetivo maior da Jornada.

As pesquisas apresentadas na II Jornada demonstram a importância de estudos sobre o fenômeno do consumo e sua relevância para compreender aspectos da sociedade contemporânea. A expansão da literatura de consumo é observada nas últimas décadas em um largo escopo de disciplinas (FEATHERSTONE, 1995; DOUGLAS e ISHERWOOD, 1996; FIRAT e VENKATESH, 1995; SLATER, 1997, 2002; MILLER, 1995; ARNOULD e THOMPSON, 2005; HOROWITZ, 2004; SCHUDSON, 1991), ultrapassando uma visão ingênua sobre o tema, como apontam Gomes e Barbosa (2004).

Assim, o consumo se mostra um fenômeno ativo e constante no cotidiano dos indivíduos, que desempenha um "papel central como estruturador de valores que constroem identidades, regulam relações sociais, definem mapas culturais" (ROCHA, 2004, p. 8). Outro aspecto relevante dos estudos sobre consumo é a percepção da amplitude do conceito para além da aquisição de bens ou reprodução física ou biológica, sendo visto como mediador de relações sociais, que é capaz de conferir status, distinguir-nos, fazer-nos sentir pertencendo a um grupo, estabelecer fronteiras, construir e fortalecer identidades e subjetividades etc. (DOUGLAS; ISHERWOOD, 2004).

Tais processos demonstram a visão a respeito da vida social a partir (também) das atividades de consumo, não somente da produção, como apontam Firat e Dholakia (1998), Schor (2007) e Gabriel e Lang (1995). Em tal reorganização, o consumo também deve ser compreendido de forma mais ampla, não apenas a partir das interpretações e significados atribuídos por consumidores mas também a partir das relações e influências que se estabelecem entre consumidores e os demais agentes de mercado, como empresas, entes reguladores, formuladores de políticas públicas, governos, legisladores, ativistas...

Os trabalhos apresentados na II Jornada possuem diversidade não apenas de temática, mas também de abordagens utilizadas e foram agrupados em cinco sessões - Moda, Consumo e Sustentabilidade; Identidade e Estilo de Vida; Consumo em Múltiplas Perspectivas; Consumo, Saúde e Alimentação; Consumo, Sociabilidades e Mercados. Este dossiê reúne alguns desses trabalhos. Os artigos "Uma análise sobre a experiência do consumo e produção em dois empreendimentos criativos da 
moda", de autoria de Luiza Silva Calado e Elaine Perdigão, e "Santa Clara 33: consumindo moda praia no bairro de Copacabana", de Alessandra de Figueredo Porto, trazem reflexões sobre o mundo da moda sob as perspectivas da produção e do consumo. No caso do primeiro, trata-se de discutir na moda a partir de casos de empreendimentos criativos em São Paulo. No segundo artigo, a autora analisa um prédio destinado ao comércio de moda praia no coração do bairro de Copacabana, no Rio de Janeiro, destacando a relação entre moda e estilo de vida. As feiras, espaços de consumo historicamente importantes no desenvolvimento da vida urbana e que vêm sendo ressignificadas na contemporaneidade, são analisadas nos artigos "A Feira Agroecológica da Serra da Misericórdia: história, sociabilidade e consumo na Zona Norte do Rio de Janeiro", de Rodrigo Rossi Morelato; "Consumo e sociabilidade numa feira de brechós no coração do subúrbio carioca", de Jorgiana Melo de Aguiar Brennand; "Consumo, sociabilidade e memória no processo de ressignificação identitária: o caso da Feira de Refugiados Chega Junto", de Conceição Souza; e "Sociabilidade e consumo da Feira das Yabás: uma observação entre práticas culturais, memória e tradição", de Adelaide Chao. Esses trabalhos, que tratam de feiras nas quais há comercialização de produtos específicos - dos produtos agrícolas aos objetos de segunda mão, mostram resultados de pesquisas que reafirmam a relevância das feiras não só como espaços de trocas, mas também de sociabilidade e de construção e reconstrução identitária e de memória.

Além do dossiê Consumo e Sociabilidades 2, este número da revista Diálogo da Economia Criativa apresenta mais cinco artigos livres, dos quais quatro também tratam do tema consumo em suas múltiplas perspectivas. Esses quatro trabalhos foram apresentados no IX ENEC - Encontro Nacional de estudos do Consumo, realizado no mês de novembro de 2018 na ESPM Rio. São eles: "Modas, calos e cetins: os sapatos como símbolos distintivos no Rio de Janeiro do século XIX", de Cecília Elisabeth Barbosa Soares e Olga Carolina Pontes Bon Velozo; "Luxos verdes na publicidade imobiliária de João Pessoa/PB", de Ceres Grehs Beck; "A construção identitária da marca Rio sob a perspectiva cultural: narrativas sobre o espaço convertido em mercadoria nos últimos 10 anos", de autoria de Brenda Stefanny Batista Neves, Wandeline De Araujo Cumarú e Hannah Miranda Morais Miranda Morais, "A construção identitária da marca Rio sob a perspectiva cultural: narrativas sobre o espaço convertido em mercadoria", de Flávia Barroso de Mello, Luís Alexandre Grubits de Paula Pessôa e Vitor Moura Lima; e fechando esta edição, o artigo "O vinho como bem de consumo que vem 'de fora': representações e práticas culturais de consumidores cariocas", de Luciana Freire Murgel.

Desejamos uma proveitosa e prazerosa leitura.

\section{Denise Franca Barros}

Michele de Lavra Pinto

Sílvia Borges Corrêa

Tânia Maria de Oliveira Almeida Gouveia

Veranise Dubeux 